\title{
Analysis of Node Velocity Effects in MANET Routing Protocols using Network Simulator (NS3)
}

\author{
Lakshman Naik L. \\ Dept.of Electronics Engg. \\ Indian Institute of Technology \\ (Banaras Hindu University) \\ Varanasi, India.
}

\author{
R. U. Khan \\ Dept.of Electronics Engg. \\ Indian Institute of Technology \\ (Banaras Hindu University) \\ Varanasi, INDIA.
}

\author{
R. B. Mishra \\ Dept.of Comp.Science \& \\ Engg. \\ Indian Institute of Technology \\ (Banaras Hindu University) \\ Varanasi, INDIA.
}

\begin{abstract}
MANET (Mobile Ad hoc Network) is an infrastructure less decentralized wireless network, which do not depend on centralized organization or switching points. MANET is a self-organizing and self-configuring network. In ad-hoc networks, routing protocols postulate communication between routers and prompt them to select routes between a source and a destination. Route choices are performed by the routing algorithms. In this paper, we used network simulator-3 to simulate comparative performance analysis of three MANET routing protocols. They are AODV (Ad-hoc On Demand Distance Vector Routing), DSDV (Destination Sequenced Distance Vector Routing) and OLSR (Optimized Link State Routing). We analyzed performance comparisons of these routing protocols using different performance metrics such as throughput, packet delivery ratio, end to end delay and packet loss.
\end{abstract}

\section{General terms}

MANET, AODV, DSDV, OLSR, RREQ, RREP, RERR DBF, MPR, TC, NS3, RWMM, PDR,EED,NRL, Throughput, Packet delivery ratio, End to end delay, Packet loss.

\section{Keywords}

Routing, Node speed, Simulation, MANET routing protocols.

\section{INTRODUCTION}

Computer networks are group of network devices and computers which shares different user services, information and user applications with each other. These are wired or wireless. Mobile ad hoc network (MANET) is a momentary wireless network which emerges without using any existing network infrastructure and without any centralized system administration. A MANET is a self-configuring and infrastructure less wireless network in which nodes are mobile in nature. Hence, topology and organization of these networks changes frequently. Nodes of MANET also perform routing activities. In mobile ad-hoc networks, due to mobility nature of nodes, routing become challenging. In MANET, routing protocols are classified in two ways; considering routing strategy, these can be classified as proactive (table-driven) and reactive (on demand) protocols and while considering organization of the network, these can be classified as flat routing; geographic position assisted routing and hierarchical routing[1]. In this paper, proactive and reactive routing protocols of MANET have been discussed with the simulation results obtained by the help of network simulator-3. Fig.1 demonstrates a simple Mobile Ad-hoc Network.

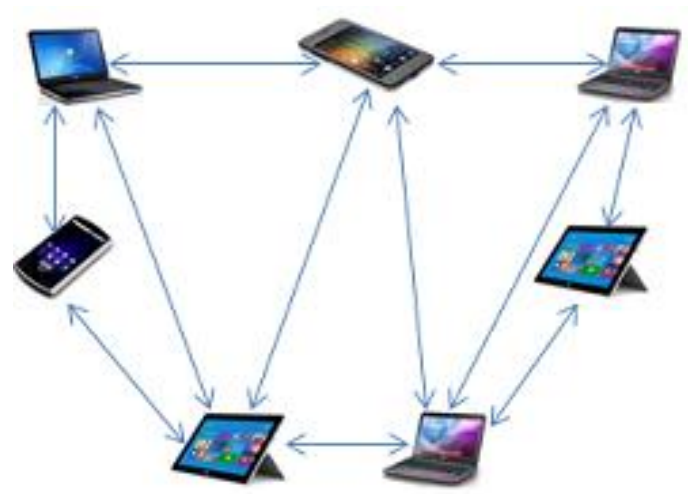

Fig.1. Mobile Ad-hoc Network

\section{MANET ROUTING PROTOCOLS}

MANET routing protocol is a resolution that controls how nodes decide the ways of routing packets between the source and a destination. In mobile ad hoc networks, nodes have to determine their network topology. A new node announces its presence and it listens to the announcements broadcast by its neighbors. MANET routing protocols are three types namely, reactive protocol (on demand), proactive protocol (table driven) and hybrid protocol. Fig.2 represents some types of MANET routing protocols [2]:

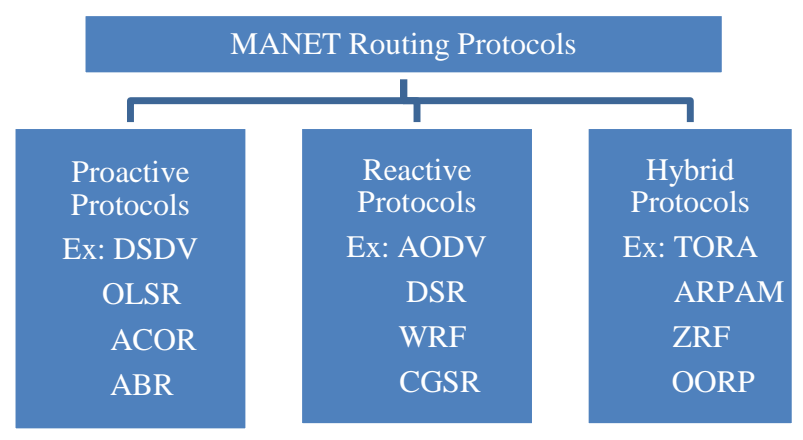

Fig.2. Types of MANET Routing Protocols [2]

MANET routing protocols related with the concerns like appeared and disappeared of nodes in different locations [3].

These routing protocols need to have smaller routing tables in order to reduce routing link overheads. 


\section{AODV (Ad hoc on demand distance vector routing protocol):}

AODV is a reactive or on demand distance vector routing protocol [4]. Ad hoc on demand distance vector routing protocol's algorithm creates routes between nodes only when the routes are requested by the source nodes, providing the network flexibility to allow nodes to enter and leave the network at will. Routes remain active only as long as data packets are travelling along the paths from the source to the destination, when the source stops sending packets, the path will time out and close. In AODV, to establish a route link to a destination, the source will broadcast a RREQ (route request) packet. Broadcasted RREQ message spread throughout the network till it reaches the destination or it gets any intermediate node that holds latest route information of the destination. While dispatching RREQ message to the destination the intermediate nodes updates RREQ information in their routing table. AODV protocol supports symmetric links only, in which network nodes maintain cache of the route and utilize the sequence number of the destination for every entry of the route. AODV has limited route discovery mechanism. When RREQ packet reaches the destination a RREP (route reply packet) will generate at the destination and it will be sent to the source. When link breaks occurs between the nodes, a RERR (route error packet) packet will be broadcasted among all the member nodes of the network. Member nodes of the network updates RERR message in their routing tables and eradicate the link breaks [5]. Fig. 3 shows the route establishment process in AODV, where $S$ is the source node, $\mathrm{D}$ is the destination node and $\mathrm{N}$ is the member node of the Network.

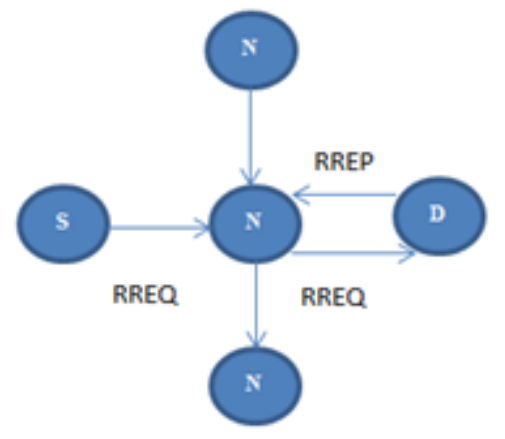

Fig. 3 Establishment of route in AODV

\section{DSDV (Destination sequenced distance vector routing protocol):}

DSDV is a proactive routing protocol based on the BellmanFord routing algorithm [3]. DSDV protocol is a modified version of the Distributed Bellman-Ford (DBF) technique that was applied effectively in almost dynamic packet switched networks. To calculate the shortest path between source and the destination, DBF technique is used. DBF technique forms some routing loops in the network. In DSDV protocol, a new parameter called Destination Sequence Number has been introduced which reduces routing loops problems of DBF technique [5]. In DSDV, all the member nodes of the network transmits a sequence number which increments periodically. Every node of the network transfers updated routing information along with the incremented sequence number to all its neighbors. This process keeps every node of the network updated with latest link information and their routing table. Nodes with latest routing information provides particular path from the source to the destination. Selection of route is takes place by means of distance vector shortest path algorithm. In DSDV, transmission overheads are minimized by means of updated packets called "full dump" and "incremental dump". The "full dump" packet holds the routing data and the incremental dump" holds only the altered data since the previous "full dump". DSDV routing protocol has large link overheads as compared to other protocols. Owing to this draw back, DSDV is utilized for small scale networks [5].

\section{OLSR (Optimized link state routing protocol):}

OLSR is a proactive routing protocol based on link state algorithm [6]. Optimized nature of OLSR routing protocol helps in reducing "flooding duplication" in highly linked networks. In OLSR, each and every node of the network exchanges network topology information periodically. The periodic nature of the OLSR generates large amount of link over heads. These link overheads are reduced by the help of MPR (Multi Point Relays). MPRs that are chosen by every node of the network as a set of neighboring nodes only forwards routing messages throughout the network periodically [7]. Routing calculations are carried out by MPR for a link from the source to the destination. OLSR routing protocol supports three types of mechanisms, which are: adequate topology information, effective flooding of control traffic and neighbor sensing [3]. Two types of control messages are used by the OLSR routing protocol, which are: HELLO and TC (Topology Control). In OLSR, to discover neighbor of the network node and link information, HELLO control messages are used. Topology Control (TC) messages are utilized to broadcast information about self- published neighbors including list of the MPR selector. In OLSR, each node transmits control messages periodically. Therefore, OLSR does not necessitate using reliable control message delivery; henceforth OLSR protocol can endure reasonable control message losses.

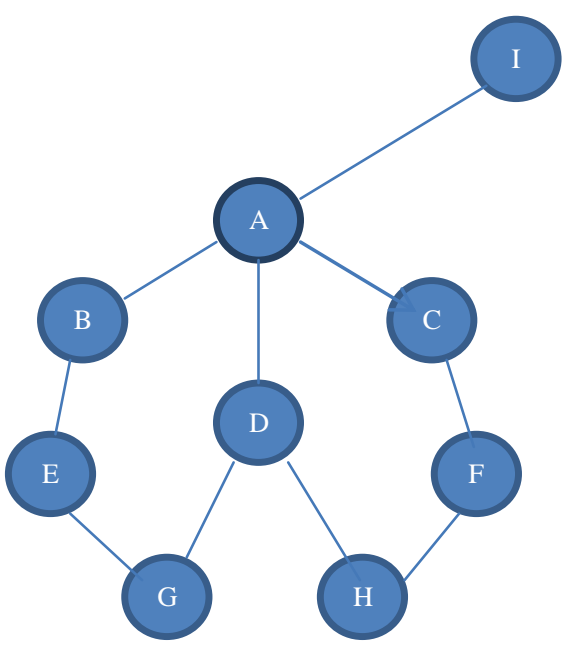

Fig. 4.Selection of MPR in OLSR.

Table1. MPR selection scenario.

\begin{tabular}{|c|c|c|c|}
\hline $\begin{array}{c}\text { Network } \\
\text { Node }\end{array}$ & $\begin{array}{c}\text { First hop } \\
\text { neighbors of } \\
\text { node A }\end{array}$ & $\begin{array}{c}\text { Second hop } \\
\text { neighbors of } \\
\text { node A }\end{array}$ & MPR \\
\hline A & B, D, C, I & E, F, G ,H & D \\
\hline
\end{tabular}

Fig. 4 and table1 illustrates the selection of MPR in OLSR. If we consider potential of node $\mathrm{A}$, both $\mathrm{C}$ and $\mathrm{D}$ cover all the 
nodes that are second hop neighbors of node A. Therefore, D is selected as B's MPR node as shown in Table 1 [13].

\section{Node Mobility:}

Mobility is the key attribute in ad-hoc networks. Modelling movement of a set of nodes is important for evaluating performance of a mobile ad-hoc network [8]. In this project, we used a typical random waypoint mobility model and Friis loss model available in NS3 (Network Simulator-3).

\section{RWMM (Random Waypoint Mobility Model):}

A mobility model describes the exact location of a mobile node at any time. The random waypoint model was originally projected by Johnson and Maltz. It is one of the most widespread mobility models to evaluate MANET (mobile ad hoc network) routing protocols, because of its ease and extensive availability [9]. "The movement of nodes is ruled in the following fashion: Each node starts by pausing for a fixed number of seconds. The node then chooses a random destination in the simulation area and a random speed between 0 and some maximum speed. The node moves to this destination and again pauses for a fixed period before another random location and speed. This performance is repeated for the total simulation time." [10].

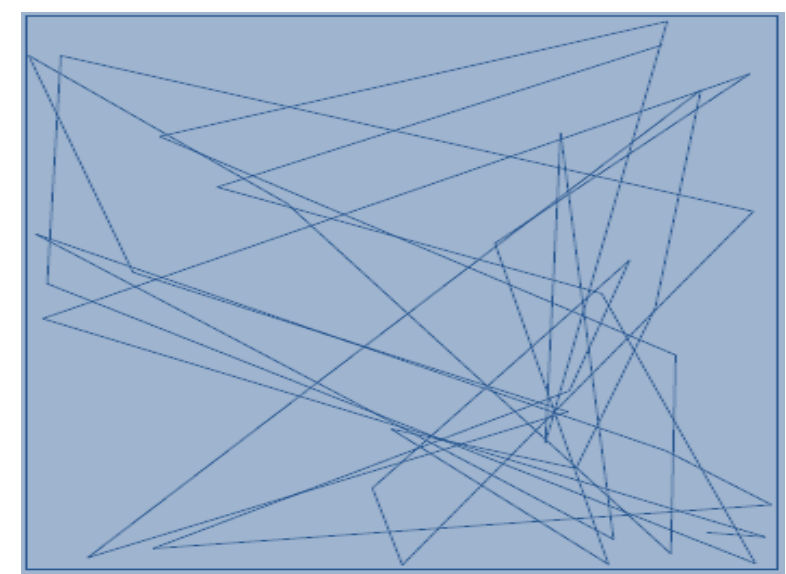

Fig.5. Movement pattern of nodes in RWMM [11].

Figure 5 illustrates the distribution of the nodes in the simulation area and the distribution of the node speeds varying over the simulation time. In RWMM, each node moves from one way point to another way point along with the zigzag line.

\section{PERFORMANCE METRICS}

There are different performance matrices available to evaluate the performances of MANET routing protocols. In this paper we discussed the following metrics [3].

\subsection{Throughput}

Throughput is the amount of data transferred from source to the destination through the network in a unit time expressed in Kbps (Kilobits per second).

Throughput $=($ Received Bytes $\times 8) \div($ Simulation time $\times 1024)$

It is derived in Kbps. Higher value of the throughput provides enhanced performance.

\subsection{PDR (Packet Delivery Ratio)}

It is the ratio of total received packets to the total packets sent.
$\mathrm{PDR}=($ total received packets $) \div($ total sent packets $) \times 100 \%$

It is derived in percentage (\%). Higher value of PDR provides enhanced performance

\subsection{EED (End to End Delay)}

End to end delay is the average time interval between packets generated at the source node and successful delivery of these packets at the destination node. It is the ratio of delay sum to the received packets.

$$
\text { End to end delay }=(\text { delay sum }) \div(\text { received packets })(3)
$$

It is derived in ms (mille second). Lesser values of end to end delay provides enhanced performance.

\subsection{Packet loss}

Packet loss is the difference of total sent packets and total received packets.

Packet loss $=($ total sent packets $)-($ total received packets $)(4)$

It is derived as number of packets.

\subsection{NRL (Normalized Routing Load)}

Normalized routing load is the fraction of the numbers of transmitted routing packets to the number of data packets received [14].

$\mathrm{NRL}=($ No. of routing packets sent $) \div($ No. of data packets received)

Higher NRL values leads to lesser efficiency of the protocol in terms of consumption of the bandwidth.

\section{SIMULATION ENVIRONMENT}

We used NS3 (Network Simulator-3) version 3.13 to simulate comparison analysis of AODV, DSDV and OLSR routing protocols of the MANET. NS3 is an open source discreteevent network simulator [12]. NS3 is developed in C++ high level programming language with the optional python bindings. NS3 has improved simulation reliability. NS3 is not retrograde attuned with NS2 (Network Simulator-2), but it was built from the scratch in order to replace APIs (Application Program Interfaces) of NS2. Some modules of NS2 have been ported to NS3. NS3 does not support APIs of NS2 [3]. We have used open source CENTOS Linux operating system to execute the simulation based experiments.

\section{SIMULATION RESULTS}

The simulation experiments and comparison of the MANET routing protocols have been carried out by keeping 10 number of source/sink connections fixed and varying node speed as 10 $\mathrm{m} / \mathrm{s}, 20 \mathrm{~m} / \mathrm{s}$ and $30 \mathrm{~m} / \mathrm{s}$. The simulation scenario and obtained results are shown in the following tables and graphs.

Table 2. Simulation Scenario of AODV, DSDV and OLSR

\begin{tabular}{|c|c|c|}
\hline 1 & Number of Nodes & 50 \\
\hline 2 & Simulation Time & 150 seconds \\
\hline 3 & Pause Time & No pause time \\
\hline 4 & Wi-Fi mode & Ad-hoc \\
\hline 5 & Wi-Fi Rate & $2 \mathrm{Mbps}(802.11 \mathrm{~b})$ \\
\hline 6 & Transmit Power & $7.5 \mathrm{dBm}$ \\
\hline
\end{tabular}




\begin{tabular}{|c|c|c|}
\hline 7 & Mobility model & $\begin{array}{c}\text { Random Waypoint } \\
\text { mobility model }\end{array}$ \\
\hline 8 & No. of Source/Sink & 10 \\
\hline 9 & Sent Data Rate & $\begin{array}{c}2048 \text { bits per second } \\
(2.048 \mathrm{Kbps})\end{array}$ \\
\hline 10 & Packet Size & 64 Bytes \\
\hline 11 & Node Speed & $\begin{array}{l}\text { First case : } 10 \mathrm{~m} / \mathrm{s} \\
\text { Second case : } 20 \mathrm{~m} / \mathrm{s} \\
\text { Third case : } 30 \mathrm{~m} / \mathrm{s}\end{array}$ \\
\hline 12 & Protocols used & $\begin{array}{l}\text { 1. AODV } \\
\text { 2. DSDV } \\
\text { 3. OLSR } \\
\text { (For all the cases) }\end{array}$ \\
\hline 13 & Region & $300 \times 1500 \mathrm{~m}$ \\
\hline 14 & Loss Model & Friis loss model \\
\hline
\end{tabular}

Table 3. Throughput results of AODV, DSDV and OLSR

\begin{tabular}{|c|c|c|c|}
\hline \multirow{2}{*}{$\begin{array}{c}\text { Node Speed } \\
\text { in } \mathrm{m} / \mathrm{s}\end{array}$} & \multicolumn{3}{|c|}{ Throughput in Kbps } \\
\cline { 2 - 4 } & AODV & DSDV & OLSR \\
\hline 10 & 13.42 & 13.59 & 18.59 \\
\hline 20 & 14.46 & 12.64 & 17.98 \\
\hline 30 & 15.15 & 14.97 & 17.86 \\
\hline
\end{tabular}

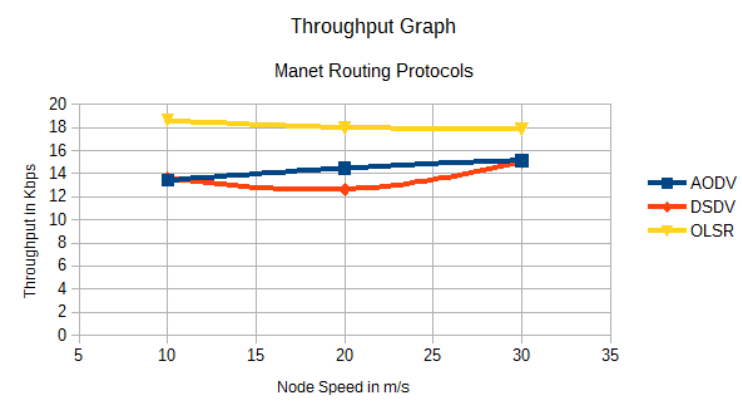

Fig. 6. Throughput over increasing node speed.

Table 4. Packet delivery ratio results of AODV, DSDV and OLSR.

\begin{tabular}{|c|c|c|c|}
\hline \multirow{2}{*}{$\begin{array}{c}\text { Node Speed } \\
\text { in } \mathrm{m} / \mathrm{s}\end{array}$} & \multicolumn{3}{|c|}{ Packet delivery ratio in \% } \\
\cline { 2 - 4 } & AODV & DSDV & OLSR \\
\hline 10 & 67.11 & 67.96 & 92.98 \\
\hline 20 & 72.33 & 63.21 & 89.93 \\
\hline 30 & 75.76 & 74.85 & 89.31 \\
\hline
\end{tabular}

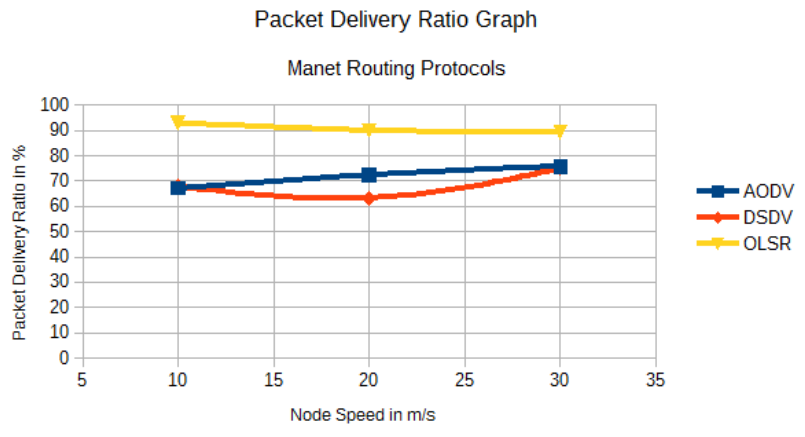

Fig. 7. PDR over increasing node speed

Table 5. End to end delay results of AODV, DSDV and OLSR

\begin{tabular}{|c|c|c|c|}
\hline \multirow{2}{*}{$\begin{array}{c}\text { Node Speed } \\
\text { in } \mathrm{m} / \mathrm{s}\end{array}$} & \multicolumn{3}{|c|}{ End to end delay in ms } \\
\cline { 2 - 4 } & AODV & DSDV & OLSR \\
\hline 10 & 0.0122 & 0.0117 & 0.0018 \\
\hline 20 & 0.0095 & 0.0145 & 0.0027 \\
\hline 30 & 0.0079 & 0.0084 & 0.0029 \\
\hline
\end{tabular}

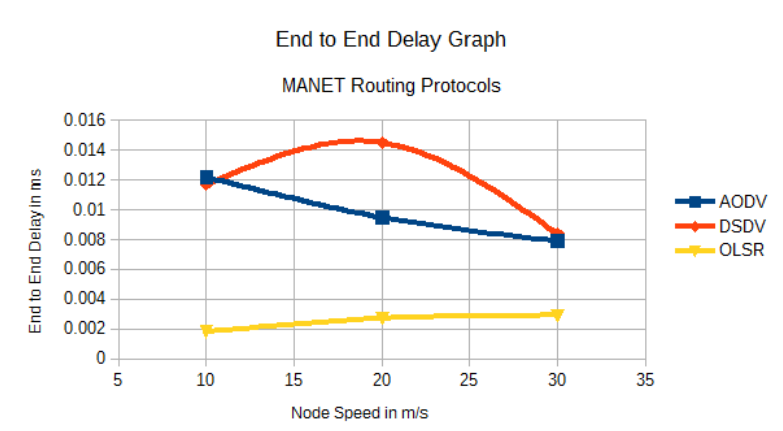

Fig. 8. End to end delay over increasing node speed Table 6. Packet loss results of AODV, DSDV and OLSR.

\begin{tabular}{|c|c|c|c|}
\hline \multirow{2}{*}{$\begin{array}{c}\text { Node Speed } \\
\text { in } \mathrm{m} / \mathrm{s}\end{array}$} & \multicolumn{3}{|c|}{ Packet loss in no. of packets } \\
\cline { 2 - 4 } & AODV & DSDV & OLSR \\
\hline 10 & 1973 & 1922 & 421 \\
\hline 20 & 1660 & 2207 & 604 \\
\hline 30 & 1454 & 1509 & 641 \\
\hline
\end{tabular}

PACKET LOSS GRAPH MANET Protocols

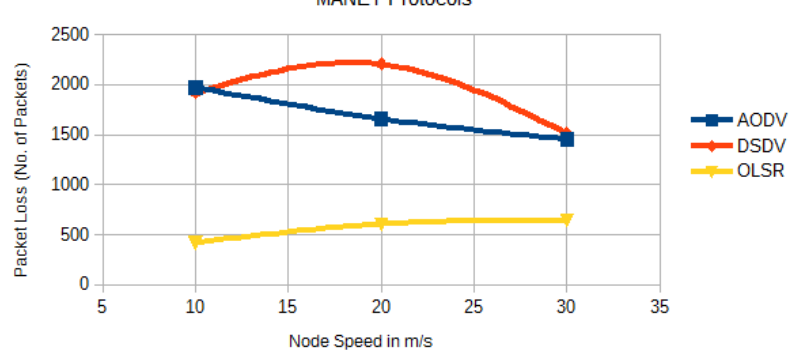

Fig. 9. Packet loss over increasing node speed. 
Table 7. NRL results of AODV, DSDV and OLSR.

\begin{tabular}{|c|c|c|c|}
\hline \multirow{2}{*}{$\begin{array}{c}\text { Node Speed } \\
\text { in } \mathrm{m} / \mathrm{s}\end{array}$} & \multicolumn{3}{|c|}{ Packet loss in no. of packets } \\
\cline { 2 - 4 } & AODV & DSDV & OLSR \\
\hline 10 & 0.671 & 0.679 & 0.929 \\
\hline 20 & 0.723 & 0.632 & 0.899 \\
\hline 30 & 0.757 & 0.748 & 0.893 \\
\hline
\end{tabular}

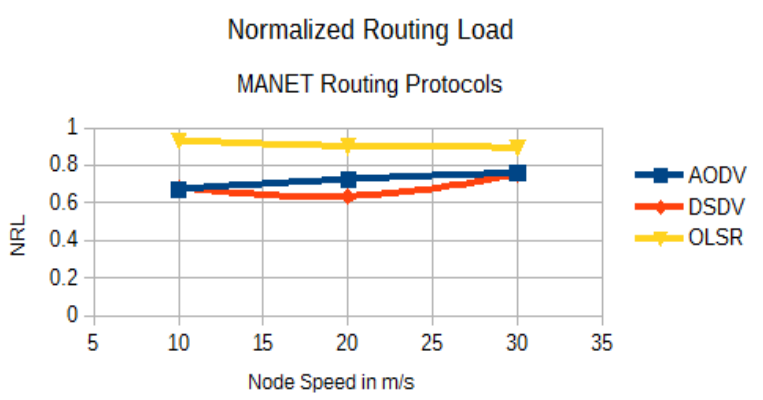

Fig. 10. NRL over increasing node speed.

\section{CONCLUSIONS AND FUTURE SCOPE}

As per our experimental results (shown in the above tables and figures), throughput of the OLSR protocol is high as compared to AODV and DSDV during node speed variation. OLSR has slight degradation in throughput as node speed increases but it is still better as compare to the AODV and DSDV. We found Throughput of AODV is high as compared to the DSDV routing protocol. Packet delivery ratio of OLSR is high as compared to AODV and DSDV but, it slightly degrades as node speed increases. As compare to DSDV, AODV has better performance in packet delivery ratio results. In End to end delay also, performance of OLSR is better as compare to the AODV and DSDV, but it slightly degrades as node speed increases. While comparing end to end delay results of AODV and DSDV, we found AODV has better performance. Packet loss results shows performance of OLSR is high as compared to AODV and DSDV, but it slightly degrades as node speed increases. Performance of AODV is high as compared to DSDV routing protocol. In NRL compilation also, OLSR is found better and AODV is better than DSDV. Therefore, finally we conclude that performance of OLSR is higher as compared to AODV and DSDV in all the metrics we analyzed. We also found that the performance of AODV is better as compared to DSDV in all the metrics we used here. However, performance of the routing protocols depends on various factors like, size of the network, no. of source/sink connections, transmission power, node speed and Wi-Fi rate. Further experiments could be carried out by increasing higher node speeds along with increasing of associated factors.

\section{ACKNOWLEDGEMENTS}

We would like to thank Dr.Ramesh Singh yadava and Dr. Chandan Kumar Rai of Computer Centre, Banaras Hindu University for their support.

\section{REFERENCES}

[1] Teressa Longjam and Neha Bagoria, February 2013. "Comparative Study of Destination Sequenced Distance Vector and Ad-hoc on-demand Distance Vector Routing Protocol of Mobile Ad-hoc Network".

[2] C. E. Perkins, E. M. Belding-Royer and S. R. Das, 25-26 February 1999. "Ad Hoc On-Demand Distance Vector (AODV) Routing," pp. 90-100. 2nd IEEE Workshop on Workshop Mobile Computing Systems and Applications, New Orleans.

[3] Rakesh Kumar Jha, Pooja Kharga, March 2015. "A Comparative Performance Analysis of Routing Protocols in MANET using NS3 Simulator".

[4] C.Perkins, RFC3561, July 2003. "Ad hoc on demand Distance Vector (AODV) routing”.

[5] Sreekanth Vakati, Dr.Ch.Balaswamy, July 2013. "Performance Analysis of Routing Protocols in Mobile Ad Hoc Networks".

[6] Dilpreet Kaur, Naresh Kumar, 2013. "Comparative Analysis of AODV, OLSR, TORA, DSR and DSDV Routing protocols in Mobile Ad-Hoc Networks," in IJCNIS journal, vol.5, no.3, pp.39.

[7] T. Clausen and P. Jaqcquet, RFC 3626, October 2003. "Optimized Link State Routing (OLSR) Protocol", IETF Networking Group.

[8] I.W.H. Ho, K.K. Leung, J.W. Polak, and R. Mangharam, Oct.2007. "Node connectivity in vehicular ad hoc networks with structured mobility," pp. 635-642, in Proc. $32^{\text {nd }}$ IEEE Conference on Local Computer Networks, Clontarf Castle, Dublin, Ireland.

[9] Johnson,D.B.;Maltz, D.A. (1996). "Dynamic Source Routing in Ad Hoc Wireless Networks". The Kluwer International Series in Engineering and Computer Science 353, p.153.

[10] Broch,J.; Maltz,D.A.;Johnson, D. B.; Hu,Y. C.; Jetcheva, J. (1998). "A performance comparison of multi-hop wire -less ad hoc network routing protocols". Proceedings of the 4th annual ACM/IEEE international conference on Mobile computing and networking - MobiCom '98(PDF), p. 85.

[11] Philipp Sommer, 2007. "Design and Analysis of Realistic Mobility Models for Wireless Mesh Networks", M. Eng. Thesis, Department of Information Technology and Electrical Engineering, Zurich, Switzerland.

[12] NS-3 tutorial. [Online]. Available: http://www.nsnam.org/docs/release/3.14/tutorial/singleht $\mathrm{ml} /$ index.html.

[13] Mohanapriya Marimuthu and Ilango Krishnamurthi, , Feb.2013. "Enhanced OLSR for Defense against DOS Attack in Ad-Hoc Networks", Journal of communications and networks, Vol. 15, no. 1, pp.31-37.

[14] Qutaiba Razouqi, Ahmed Boushehri, Mohamed Gaballah, Lina Alsaleh, 2013. "Extensive Simulation Performance Analysis for DSDV, DSR, and AODV MANET Routing Protocols. IEEE. 